\title{
Nanostructured Ni Based Anode and Cathode for Alkaline Water Electrolyzers
}

\author{
Fabrizio Ganci ${ }^{1}$ (), Tracy Baguet ${ }^{2}$, Giuseppe Aiello ${ }^{1}$, Valentino Cusumano ${ }^{1}$, Philippe Mandin ${ }^{2}$, \\ Carmelo Sunseri ${ }^{1}$ and Rosalinda Inguanta ${ }^{1, * \mathbb{C}}$ \\ 1 Dipartimento di Ingegneria, University of Palermo, Viale delle Scienze, 90128 Palermo, Italy; \\ fabrizio.ganci@unipa.it (F.G.); giuseppe.aiello03@unipa.it (G.A.); c.valentino91@gmail.com (V.C.); \\ carmelo.sunseri@unipa.it (C.S.) \\ 2 Département Génie thermique et énergie, Université de Bretagne Sud, IRDL UMR CNRS 6027, 56325 Lorient, \\ France; baguet.tracy@outlook.fr (T.B.); philippe.mandin@univ-ubs.fr (P.M.) \\ * Correspondence: rosalinda.inguanta@unipa.it
}

Received: 9 August 2019; Accepted: 23 September 2019; Published: 25 September 2019

check for updates

\begin{abstract}
Owing to the progressive abandoning of the fossil fuels and the increase of atmospheric $\mathrm{CO}_{2}$ concentration, the use of renewable energies is strongly encouraged. The hydrogen economy provides a very interesting scenario. In fact, hydrogen is a valuable energy carrier and can act as a storage medium as well to balance the discontinuity of the renewable sources. In order to exploit the potential of hydrogen it must be made available in adequate quantities and at an affordable price. Both goals can be potentially achieved through the electrochemical water splitting, which is an environmentally friendly process as well as the electrons and water are the only reagents. However, these devices still require a lot of research to reduce costs and increase efficiency. An approach to improve their performance is based on nanostructured electrodes characterized by high electrocatalytic activity. In this work, we show that by using template electrosynthesis it is possible to fabricate Ni nanowires featuring a very high surface area. In particular, we found that water-alkaline electrolyzers with $\mathrm{Ni}$ nanowires electrodes covered by different electrocatalyst have good and stable performance at room temperature as well. Besides, the results concern nickel-cobalt nanowires electrodes for both hydrogen and oxygen evolution reaction will be presented and discussed. Finally, preliminary tests concerning the use of Ni foam differently functionalized will be shown. For each electrode, electrochemical and electrocatalytic tests aimed to establishing the performance of the electrolyzers were carried out. Long term amperostatic test carried out in aqueous solution of $\mathrm{KOH}$ will be reported as well.
\end{abstract}

Keywords: alkaline electrolyzers; nickel; nanostructures; Ni-alloy; iridium oxide; cobalt; palladium; nanowires; foam; electrocatalysts

\section{Introduction}

In recent years, there has been an increase in global energy demand caused by many factors, such as the increase in world population and the improvement in the standard of living-especially in developing countries [1,2]. The increasing energy demand, together with other factors, such as climate change, the depletion of fossil fuels, environmental pollution, security of supply, etc., is creating an urgent need to develop new energy strategies with limited emissions of greenhouse gases and with a high ease of supply [3,4]. The only possible strategy is the adoption on a global scale of high-efficiency energy technologies and the exploitation of renewable energy sources (RES), capable of combining the development needs of individual countries and protecting the environment, [5]. Among them, hydrogen is a valuable energy carrier, which can act as a storage medium to balance the discontinuity of the renewable sources, as shown in Table 1. 
Table 1. Specific energy and energy density comparison between hydrogen and other fuels.

\begin{tabular}{ccccccc}
\hline Properties & Hydrogen & Methane & Gasoline & Diesel & LPG & Methanol \\
\hline Specific energy [MJ/kg] & 141.86 & 55.6 & 46.4 & 45.6 & 49.6 & 19.87 \\
Energy density [MJ/L] & 10.044 (liquid) & 22.2 & 34.2 & 38.6 & 25.3 & 15.6 \\
\hline
\end{tabular}

Hydrogen is currently made via steam-methane reforming, which produces greenhouse gases and thus cannot be considered an environmentally friendly process. Water electrolysis is a real alternative process and represents a fundamental stage of the hydrogen economy (HE). HE consists in the production of electrolytic hydrogen from the surplus electricity of renewable sources and is then used as fuel to produce energy when it is the most in demand [6-10]. Focusing on the hydrogen production through electrolysis, the HE chain can be summarized in four steps (as shown in Figure 1):

- The first phase is the production of hydrogen through electrochemical cells (electrolyzers) powered by renewable sources.

- The post-production phase is the hydrogen storage. Hydrogen storage methods can be classified into physical methods, such as compression, and chemical methods, such as metal hydrides.

- The third phase consists in the transport of hydrogen from the point of production to the place of consumption-which must not necessarily coincide.

- The last phase of the supply chain is the conversion of hydrogen into electricity or into other forms of energy. In fact, hydrogen can be converted into electricity through fuel cells. However, this should not exclude the possibility of using hydrogen as a fuel in heat engines or boilers, converting hydrogen into mechanical energy and thermal energy, respectively.

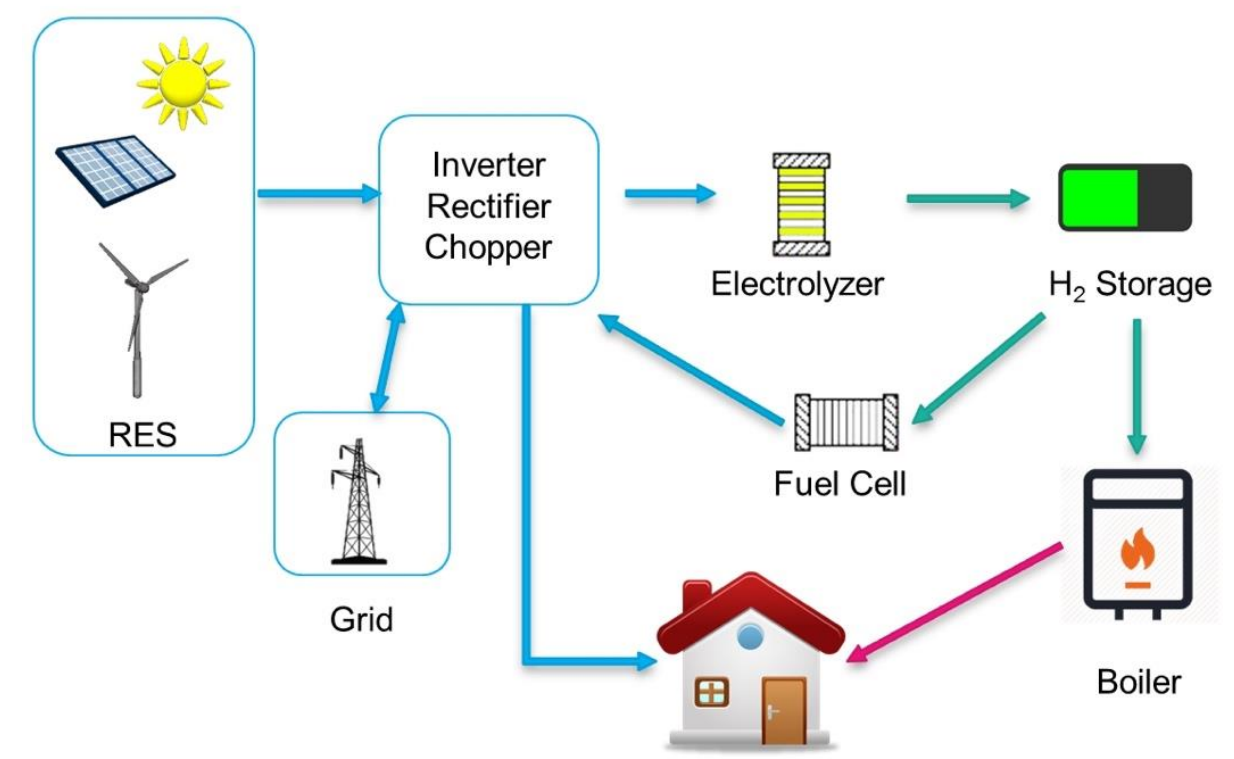

Figure 1. A possible scheme of production of hydrogen and its use in hydrogen economy.

The application of HE has the potential advantage of not dispersing the surplus energy of renewable energies, which would otherwise be cut by the introduction into the grid. Instead, this surplus can be used to produce hydrogen that is a decarbonized and therefore an emission free energy carrier, usable in a large number of applications where fossil fuels are currently used, allowing a global reduction of $\mathrm{CO}_{2}$ emissions into the atmosphere [11].

It is a common opinion that water splitting driven by renewable sources is the only way to achieve both a clean and simultaneously abundant production of hydrogen [12,13]. It is common opinion as well that innovative electrochemical cells should be developed in order to reduce the energy 
required per unit mass of produced hydrogen [14], (including the increase in entropy, the required thermodynamic value for hydrogen production is 79.3 Wh per mol of $\left.\mathrm{H}_{2}[15,16]\right)$. To reduce the electrolyze running costs, the main strategies are the use of high surface area electrodes, which can support efficient catalysts as well [17-19] (with the aim to reduce the load, thus lowering the costs), and at the same time the development of electrodes suitable for photo-water splitting [20-22].

In order to increase the efficiency, we have focused our attention on the optimization of the $\mathrm{i}-\mathrm{V}$ electrolyze characteristic. In the $\mathrm{i}-\mathrm{V}$ characteristic, the two major dissipative contributions are due to reaction overvoltage and ohmic drop $[23,24]$. Reaction overvoltage depends on the electrode materials and on the electrocatalysts, while ohmic drop is related to engineering of the cell. The electrode materials and catalysts depend on the nature of the electrolyte. In particular, precious metals or their alloys are used for water splitting in acidic aqueous solutions, supported on porous carbonaceous materials [25-28]. In alkaline electrolytes, cheaper materials, such as $\mathrm{Ni}$ and its alloys [29-32], are used instead. Besides, different electrocatalysts in acidic and basic electrolyte are employed for hydrogen evolution reaction (HER) [33,34], and for the highly irreversible oxygen evolution reaction (OER) [35,36], as shown in Figure 2. Finally, very different materials are used in the case of solid oxide electrolyzers operating at high temperatures $[37,38]$.

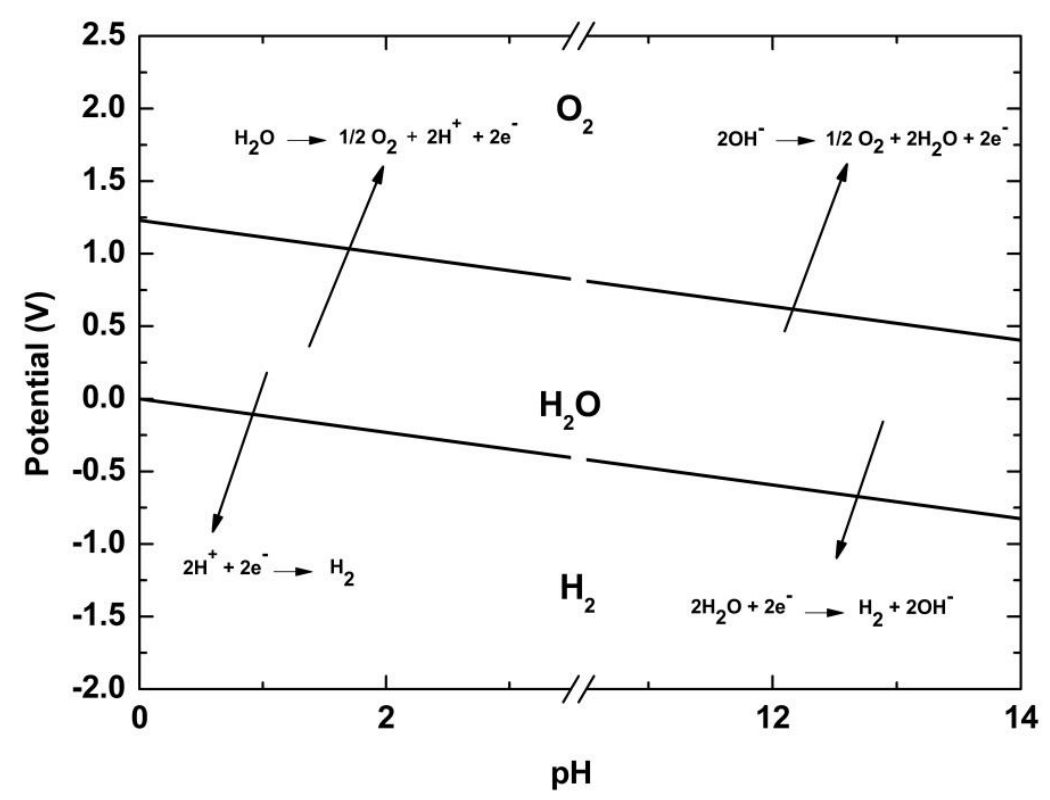

Figure 2. Hydrogen evolution reaction (HER) and oxygen evolution reaction (OER) in acidic and basic electrolyte, respectively.

Among the different electrolyzer technologies, the alkaline electrolyzers have been the most successful from a commercial point of view, as they are the simplest and cheapest option [39-41]. Despite being commercial devices, research on alkaline electrolyzers is still very active in order to optimize their operation and increase efficiency. In addition, a lot of effort is being made to develop alkaline electrolyzers that enable chlorine-free electrolysis from seawater [42].

For improving the electrode catalytic activity, both nanostructured anode and cathode have been extensively investigated [43-46]. In fact, the use of nanostructured materials is a strategy employed by several researchers because reaction overvoltage strongly depends on electrode surface area [47]. In this context, the template electrochemical methods play a relevant role for nanostructured electrode fabrication usable in different devices [48-51]. Particularly, we have focused our attention on the template electrosynthesis of ordered array of Ni nanowires (Ni-NWs). These electrodes have a surface area about 70 times higher than geometrical one, and can be functionalized with different electrocatalysts both for HER and OER [52-55]. Ni was selected owing to its low cost and high chemical stability in alkaline environment and because it is part of the strategy pursued by several researchers 
to develop catalysts based on earth abundant transitional metals [36,56]. Besides, we have studied the behavior of $\mathrm{Ni}$ foam covered with different catalysts as well. In both cases, with Ni nanowires and foam, the functionalization with electrocatalysts was achieved by means of electrodeposition and galvanic displacement deposition, which are very easy and low-cost methods.

In particular in this work, the performance of nanostructured composite electrodes of $\mathrm{Ni} / \mathrm{IrO}_{2}$, $\mathrm{Ni} / \mathrm{Pd}$ and $\mathrm{Ni}-\mathrm{Co}$ alloy have been studied. Electrochemical and electrocatalytic characterization were carried out to estimate the properties of nanostructured for HER and OER in an alkaline medium. Moreover, in order to simulate the operation in electrolyzers, the electrodes were tested at constant current density for different hours. Some preliminary results were reported in $[57,58]$.

\section{Materials and Methods}

Ni NWs substrates were fabricated by a two-step procedure consisting of deposition of a thin layer of $\mathrm{Ni}$, which acts as current collector, followed by nanowires deposition [54,58,59]. For nanowires, a pulsed unipolar electrodeposition into the pores of the polycarbonate membrane was used, following the procedure reported in [52]. In particular, a trapezoidal wave, with potential pulsed between -0.12 and $-0.83 \mathrm{~V}$ versus Reversible Hydrogen Electrode (RHE) and a scan rate of $0.1 \mathrm{~V} \mathrm{~s}^{-1}$, was used. As reported in [53], this wave shape allows to produce Ni nanowires with uniform length, on the entire surface of template. The electrodeposition solution is the typical Watts's bath (300 g/l Nickel Sulphate Hexahydrate, $45 \mathrm{~g} / 1$ Nickel Chloride, $45 \mathrm{~g} / 1$ Boric Acid) at $3 \mathrm{pH}$. After deposition, a template was etched in pure dichloromethane at room temperature in order to obtain NWs conformal to the template and well adherent to the current collector as well.

Functionalization with Iridium oxide: Iridium oxide was deposited electrochemically into the array of Ni nanowires by pulsed electrodeposition with a rectangular wave ( 500 cycles between 0.0 (for $1 \mathrm{~s}$ ) and $1 \mathrm{~mA} \mathrm{~cm}^{-2}$ (for $1 \mathrm{~s}$ )) using a Dimensionally Stable Anode (DSA) as counter-electrode. Electrodepositions of iridium oxide were performed at room temperature from a de-aerated solution of $\mathrm{Ir}_{2} \mathrm{O}_{3} \times \mathrm{H}_{2} \mathrm{O}$, following the procedure proposed in [54]. The performances of Ni nanowires electrodes were compared to Ni sheet, with flat morphology, without iridium oxide, since these types of composite electrodes were extensively investigated in the literature [60,61].

Functionalization with palladium nanoparticles: Pd nanoparticles were deposited by galvanic displacement deposition using Ni NWs as substrate. For galvanic deposition, an aqueous solution of 5 $\mathrm{mM} \mathrm{Pd}\left(\mathrm{NH}_{3}\right)_{4}$ with $0.1 \mathrm{M} \mathrm{H}_{3} \mathrm{BO}_{3}$ was used [58]. The solution was acidified up to a $\mathrm{pH}$ of about 2 using $\mathrm{HNO}_{3}$ and the process was carried out at room temperature. Ni NWs was simply immersed in this solution, which was sonicated to ensure its permeation throughout the entire NWs length.

Galvanic deposition is a spontaneous process driven by the difference of electrochemical redox potential between $\mathrm{Pd}$ and $\mathrm{Ni}$. The global reaction is (reaction 1):

$$
\mathrm{Ni}+\mathrm{Pd}^{2+} \rightarrow \mathrm{Ni}^{2+}+\mathrm{Pd}
$$

The process starts just after the immersion of $\mathrm{Ni}$ in solution, and in particular the dissolution of $\mathrm{Ni}$ occurs producing the electrons for palladium ion reduction, as shown in Figure 3.

Fabrication of Ni-Co alloy: Ni-Co nanowire arrays were produced with a similar procedure used for the fabrication of Ni nanowires. Watt's bath was used for the Ni deposition, while the Co deposition bath was composed of $300 \mathrm{~g} / \mathrm{L}$ Cobalt Sulfate Heptahydrate, $45 \mathrm{~g} / \mathrm{L}$ Cobalt Chloride and 45 $\mathrm{g} / \mathrm{L}$ Boric Acid at pH 3 [57]. For Ni-Co deposition, in order to obtain alloy with tuned composition, the above baths were mixed in different volumetric ratio. Nanowires were obtained by pulsed potential electrodeposition in polycarbonate template using the same potential wave of Ni NWs deposition above described.

Functionalization of Ni foam: Ni foam was functionalized with Pd and Ni-Co alloy. Composite $\mathrm{Ni}$ foam/Pd was obtained by galvanic displacement deposition, Figure 4. Composite Ni foam/Ni-Co 
alloy was obtained by potentiostatic electrodeposition, mixing the solutions of $\mathrm{Ni}$ and Co deposition in a 2:1 volumetric ratio.

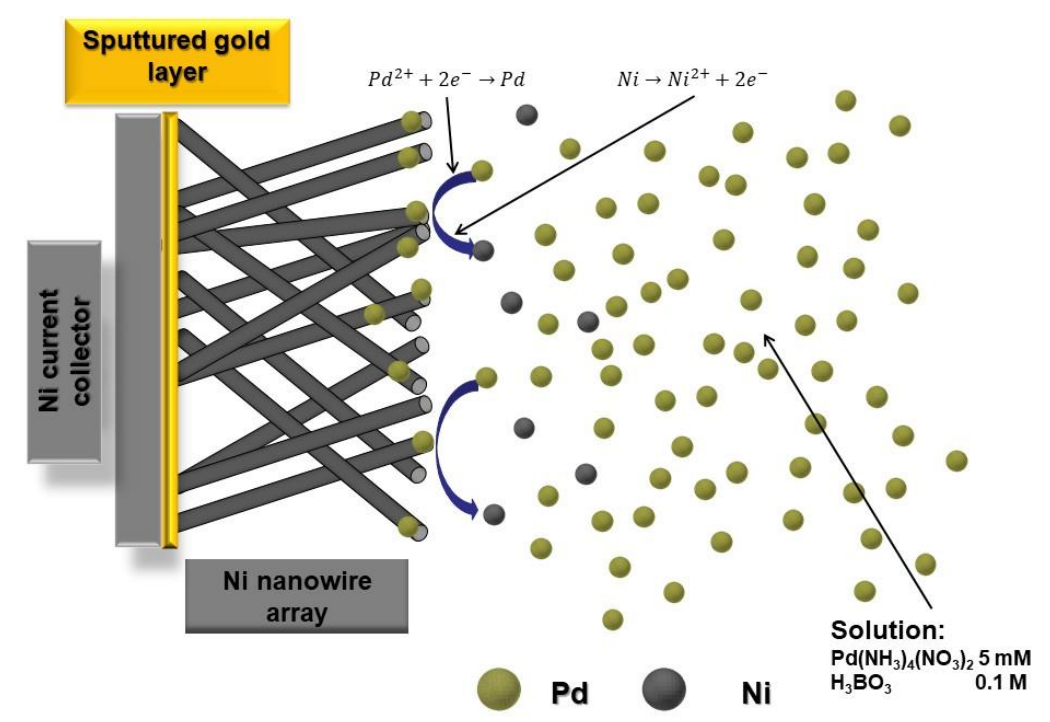

Figure 3. Scheme of galvanic displacement deposition of Pd on Ni-NWs.

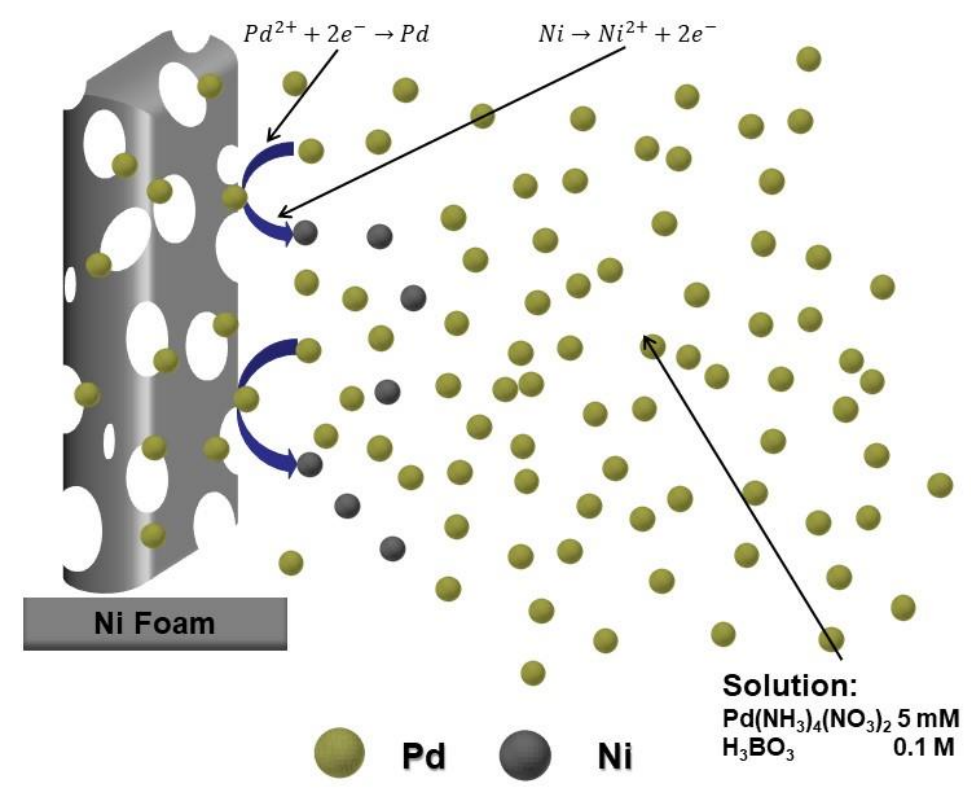

Figure 4. Scheme of galvanic displacement deposition of Pd on Ni-foam.

In all cases, electrodeposition and electrochemical characterization were performed using a Cell Test System (model: Mod. 1470 E, 8 channels, Solartron Analytical, Leicester, United Kingdom). Morphology was investigated using a FEG-ESEM microscope (model: QUANTA 200 by FEI, Thermo Fisher Scientific, Waltham, MA, USA), while composition was estimated by Energy Disperse Spectroscopy (EDS). A RIGAKU X-ray diffractometer was used to investigate the crystallographic structure (model: D-MAX 25600 HK, Tokyo, Japan). All characterization methods are detailed in [62-64]. Electrodes were electrochemical characterized by cyclovoltammetry (CV) and quasi-steady-state polarization (QSSP) in $\mathrm{KOH}$ solution at room temperature. In the same solution, the performance of electrode with and without catalyst was evaluated as detailed in [53-55]. 


\section{Results and Discussion}

\subsection{NWs Behavior with Iridium Oxide}

$\mathrm{Ni}-\mathrm{IrO}_{2}$ electrodes for OER were obtained by pulsed electrodeposition of Ni nanowires. Prior to electrocatalytic characterization, prepared electrodes were analyzed by XRD and SEM. From the patterns of Figure $5 \mathrm{a}$-where Ni NWs were reported before and after the deposition of $\mathrm{IrO}_{2}$ - it can be concluded that the iridium oxide deposit consists of an amorphous phase in agreement with the result obtained by Yamanaka [65]. In fact, on both patterns only the peaks of nickel were found, but in the pattern of functionalized NWs the intensity of these peaks is considerably lower. This result can be attributed to an amorphous deposit screening the peaks of Ni NWs support. The presence of iridium oxide was confirmed as well by EDS spectroscopy (Figure S2). Figure 5b shows the SEM image of functionalized nanowires. In comparison to as obtained Ni NWs (Figure S1), this image shows the $\mathrm{IrO}_{2}$ deposit cover with a thin layer on the surface of the nanowires. This morphology is more different of that obtained in [54], where iridium oxide was deposited by three different electrochemically ways (potentiostatically, galvanostatically and by cyclic voltammetry). The electrochemical characterization of samples was performed by CV and quasi-steady state polarization (QSSP). Both tests were carried-out in $1 \mathrm{M} \mathrm{KOH}$ solution at room temperature using a two-compartment cell connected through a salt bridge (made of Agar-Agar in $\mathrm{KNO}_{3}$ saturated solution), which assurances the electrolytic continuity. $\mathrm{CV}$ curves were measured in the potential range from 1 to $1.6 \mathrm{~V}$ vs. RHE with a scan rate of $10 \mathrm{mV} \mathrm{s}{ }^{-1}$, while QSSP curves were recorded between 2.4 and $3.2 \mathrm{~V}$ versus RHE at a rate of $0.167 \mathrm{mV} \mathrm{s}^{-1}$. As is evident in Figure 5c, from Ni sheet to Ni NWs, an increase of peak current can be observed. This increase is about two orders of magnitude, as reported as well in previous works [53]. Considering that all CV were recorded at the same potential scan rate of $10 \mathrm{mV} \mathrm{s}^{-1}$, such an increase of the area underlying peaks can be attributable to the high surface area of nanostructures. For functionalized NWs with $\mathrm{IrO}_{2}$, the further increase of peak current is due to the electrocatalytic activity of the iridium oxide, which is known to be one of the best electrocatalysts for the OER [66,67]. The anodic peak at about 1.39/1.43 V (RHE) (and the corresponding cathodic peak at 1.3/1.27 V) is attributable to the redox couple $\mathrm{Ni}(\mathrm{OH})_{2} / \mathrm{NiOOH}$ as reported by Schrebler Guzmán et al [68].

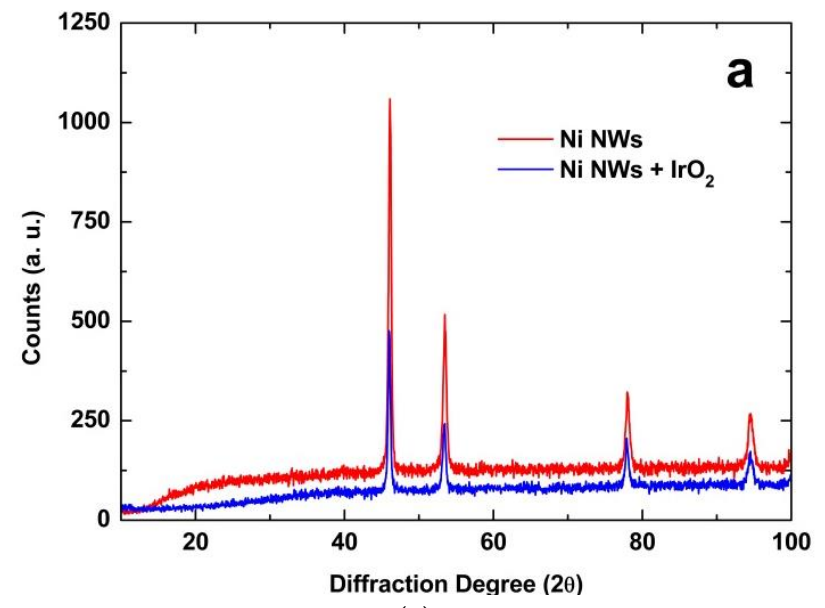

(a)

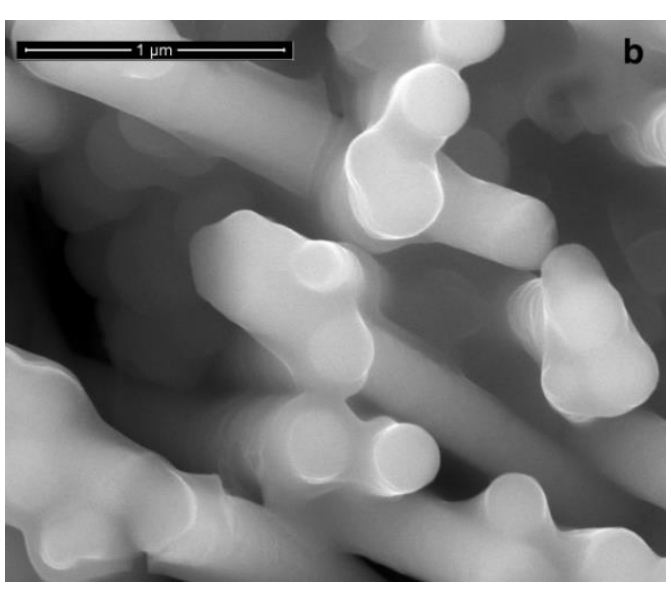

(b)

Figure 5. Cont. 


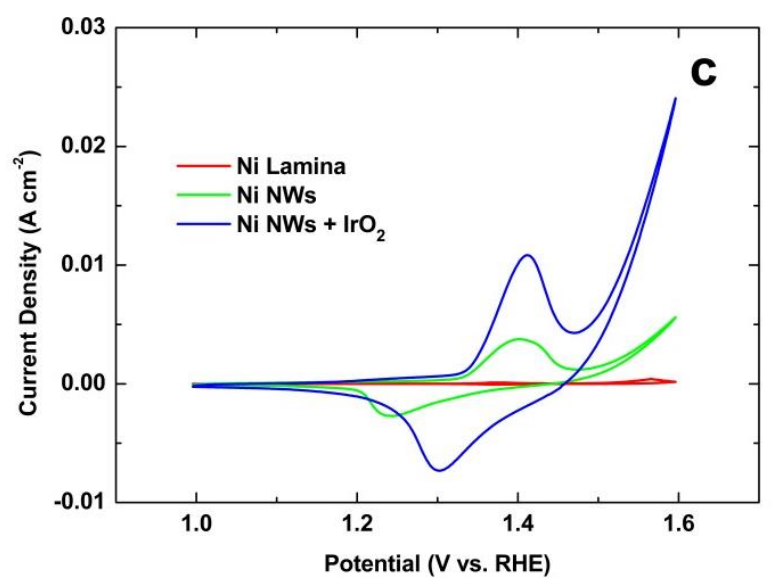

(c)

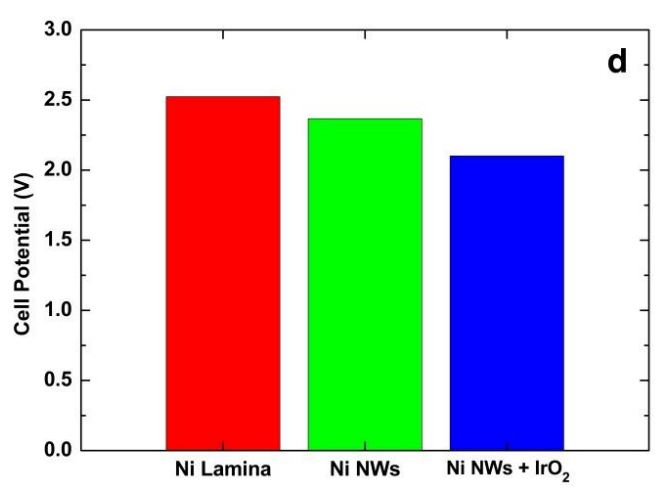

(d)

Figure 5. (a) XRD diffraction patterns of Ni NWs without and with iridium oxide electrocatalyst; (b) SEM image of functionalized Ni NWs; (c) CV and (d) cell potential of Ni NWs without and with iridium oxide electrocatalyst. For comparison, the behavior of the Ni sheet was reported as well.

The positive influence of $\mathrm{IrO}_{2}$ to improve the electrocatalytic behavior of Ni NWs for OER is shown as well in Figure $5 \mathrm{~d}$ where the mean values (for about a work time of $48 \mathrm{~h}$ ) of cell potential are reported. These values refer to nanostructured electrode assembled in an alkaline electrolyzers, using a Ni sheet as cathode and an aqueous $1 \mathrm{M} \mathrm{KOH}$ electrolyte with $1 \mathrm{~cm}$ of inter-electrode distance, working at a constant current density of $100 \mathrm{~mA} \mathrm{~cm}^{-2}$ at room temperature. Clearly, functionalized iridium oxide nanowires show the lower potential value. This result was confirmed as well by QSSP measure (Figure S3) showing that, for the same potential value, Ni-NWs/ $/ \mathrm{IO}_{2}$ have the highest current for the OER. The obtained results are very interesting because we have obtained a current density value at $2.1 \mathrm{~V}$ (cell potential) at room temperature, which was very close to that obtained by Li et al [31] at $55{ }^{\circ} \mathrm{C}$.

\subsection{NWs Behavior with Palladium Nanoparticles}

$\mathrm{Ni}-\mathrm{Pd}$ nanostructured electrodes, fabricated through the combination of electrochemical and galvanic deposition, were investigated for HER [58]. Pd was selected because it is well known that it is a very good electrocatalysts for HER, being a catalyst of precious metals group [30,33,69,70]. Pd nanoparticles were deposited on electrochemical obtained Ni-NWs by the spontaneous displacement deposition, and its presence was confirmed by EDS spectroscopy (Figure S4).

We found that, by simply adjusting the deposition time, it is possible to control the loading of the electrocatalyst on the surface of nanowires. This is well clear from the comparison of SEM images of Figure $6 \mathrm{a}, \mathrm{b}$, showing the effect of galvanic deposition time on the Pd load into Ni NWs. After $1 \mathrm{~min}$ of deposition, Pd nanoparticles have a spherical shape, with a mean diameter of about $60 \pm 5 \mathrm{~nm}$, and are randomly distributed on the lateral surface of the Ni NWs. In the cross-sectional view of this sample, Figure 6c, it can be seen as well that nanoparticles are not present on the entire length of nanowires, but only in the last $1-1.5 \mu \mathrm{m}$, which is the top of the array and the zone exposed to the galvanic deposition bath. In the sample obtained after 5 min of deposition, an increase of the Pd load is clearly visible. In particular, it is possible to observe that the head of the nanowires is completely covered with large palladium particles of about $110 \pm 5 \mathrm{~nm}$, formed by the coalescence of neighboring nanoparticles. Additionally, in this sample, the nanoparticles are present on the lateral surface of the nanowires only for a few $\mu \mathrm{m}$ from the head. 


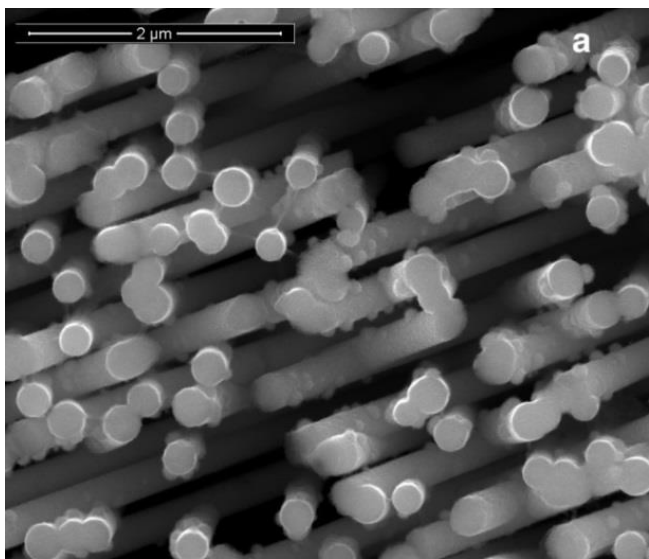

(a)

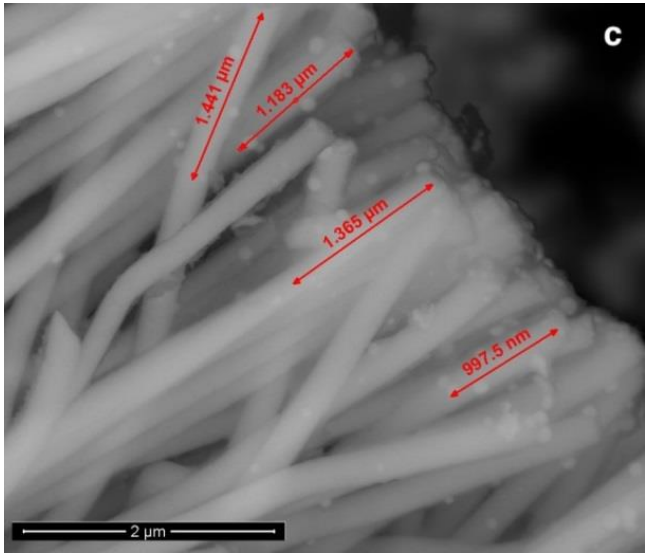

(c)

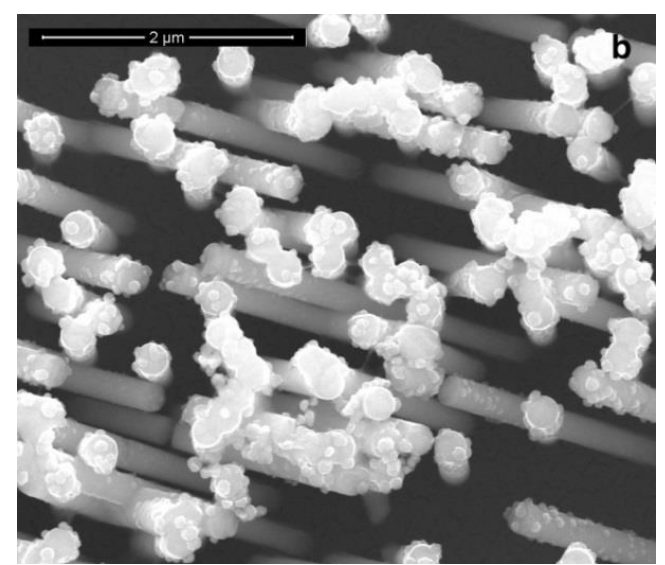

(b)

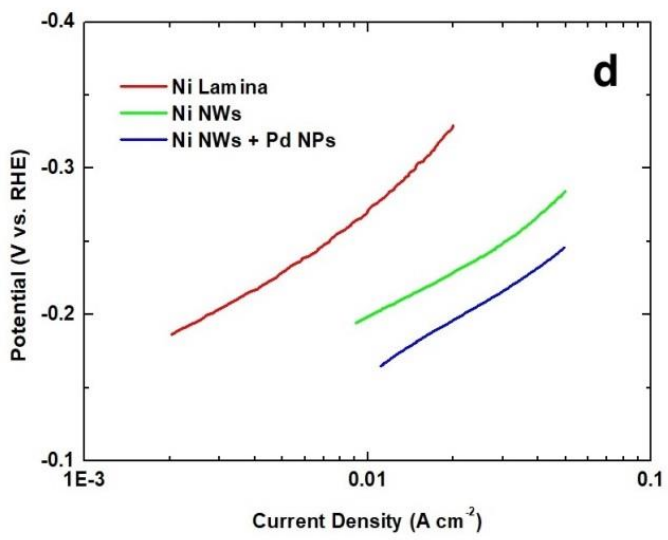

(d)

Figure 6. SEM image of Ni NWs with Pd nanoparticles obtained (a) after $1 \mathrm{~min}$ a and (b) $5 \mathrm{~min}$ of galvanic displacement deposition (c) cross-sectional view of sample of Figure 6a; (d) QSSP of Ni NWs without and with Pd nanoparticles. For comparison, the behavior of Ni sheet was reported as well.

$\mathrm{Ni}-\mathrm{Pd}$ cathodes were tested in $30 \% \mathrm{w} / \mathrm{w} \mathrm{KOH}$ aqueous solutions at room temperature and Figure 6d shows the QSSP curves. The potential was scanned from 0 to $-0.5 \mathrm{~V}$ (versus RHE) at a scan rate of $0.167 \mathrm{mV} \mathrm{s}^{-1}$. In the plot, only the linear behavior was reported. For HER, Ni-Pd electrodes have better performance than other samples (Ni NWs and Ni sheet). This behavior was attributed to the high catalytic activity towards hydrogen evolution of the palladium. QSSP were fitted by the Tafel's model (Equation (2)), to exactly evaluate the slope:

$$
\eta=a+b \log i
$$

Table 2 reports the value of $\mathrm{a}$ and $\mathrm{b}$ parameters, related to exchange current density and the slope of the Tafel's curves respectively. Ni NWs without and with palladium nanoparticles have the lower slope. This is a very interesting result, because the lower the value of the parameter $b$ is, the better the electrocatalytic performances are. Thus, it is possible to conclude that as prepared and composite Ni nanowires have the lowest overpotential for the HER and thus the best performance. In Table 2 the mean value of potential (referred to nanostructured electrode assembled in an alkaline electrolyzers, using a Ni sheet as anode and an aqueous electrolyte of $30 \%$ of $\mathrm{KOH}$ with $1 \mathrm{~cm}$ of inter-electrode distance, working at a constant current density of $0.05 \mathrm{~A} \mathrm{~cm}^{-2}$ and room temperature) was reported as well.

Despite the QSSP curves showing that the Ni-Pd composite nanowires have the highest current for the development of hydrogen (for the same voltage value), the operation of the electrode in a cell that simulates an alkaline electrolyze is very similar to that of pure Ni nanowires. In reality, at the beginning of the electrolyze operation, Ni-Pd nanowires cathode shows a lower reaction overpotential 
than Ni NWs. However, considering that Pd is a sponge for hydrogen, the progressive adsorption of hydrogen on Pd nanoparticles makes Ni-Pd nanowires very similar to nickel ones-and, in fact, very similar cell potential were measured as evident in Table 2 [53].

Table 2. Fitted Tafel parameters for HER and potential mean value for a mid-term galvanostatic test at $0.05 \mathrm{~A} \mathrm{~cm}^{-2}$, in an aqueous $\mathrm{KOH} 30 \% \mathrm{w} / \mathrm{w}$ solution at room temperature.

\begin{tabular}{cccc}
\hline Electrode & $\mathbf{a}(\mathbf{V})$ & $\mathbf{b}(\mathbf{V} / \mathbf{d e c})$ & Potential (V vs. RHE) \\
\hline Ni Lamina & -0.560 & -0.142 & -0.980 \\
Ni NWs & -0.431 & -0.118 & -0.703 \\
Ni NWs + Pd NPs & -0.400 & -0.120 & -0.734 \\
\hline
\end{tabular}

\subsection{Behavior of Nanowires of Ni-Co Alloy}

$\mathrm{Ni}$ is the most used material in the alkaline environment even if, during the operation, it is subjected to deactivation due to the formation of nickel hydrides [71]. To overcome this problem, we have alloyed nickel with Co in this work because it has been demostrated that the use of alloy prevents the formation of hydrides and improve electrode stability [72,73]. Nanowires of Ni-Co alloy were fabricated by electrodeposition using polycarbonate as template. In order to compare the performance of the alloy, pure $\mathrm{Ni}$ and Co nanowires were fabricated as well. The composition of nanowires was controlled by tuning the electrolyte composition, which was an aqueous solution of $\mathrm{Ni}$ and Co salts in different concentration. The formation of alloy was demontrated by EDS spectroscospy and XRD diffraction. From XRD, in the pattern of pure NWs $C_{0}$, the presence of $\varepsilon$-Co peaks was found (hcp lattice), while pure Ni nanowires have a similar spectrum of that reported in Figure 5, which corresponds to crystalline $\alpha-\mathrm{Ni}$ with fcc structure. With the increase of $\mathrm{Ni}$ content in the alloy, a gradual shift of the Co diffraction peaks towards the characteristic peaks of pure Ni was observed. The composition of alloy was calculated by EDS, performing the analisis in different points of the nanowires in order to verify its homogeneity. In Figure 7, the EDS spectra of nanowires with a different composition were reported. We found that, and in agreement with literature data, Co content is higher in the alloy than in the deposition bath [74]. This behavior is imputable to the presence of boric acid in the deposition bath. In fact, although the standard electrochemical potential of Ni is slightly higher than that of $\mathrm{Co}$, the formation of Co-Borate complex, which has a stability constant lower than Ni-Borate ones, favours the deposition of Co [75]. Morphology of the nanostructured alloy (Figure S5) is practally indentical to that of pure Ni nanowires.

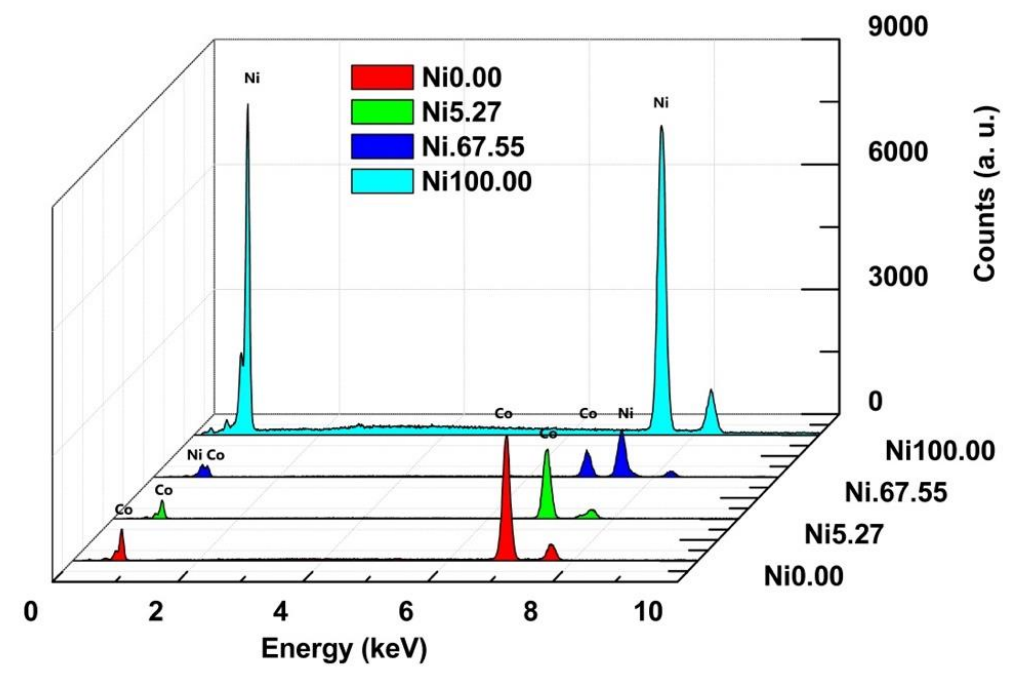

Figure 7. EDS spectra of Ni-Co alloy nanowires with different composition obtained by electrodeposition in polycarbonate membranes. 
$\mathrm{Ni}$-Co alloy electrodes were tested both as cathode and anode for the water splitting reaction in an aqueous solution of 30\% w/w $\mathrm{KOH}$ at room temperature. In Figure 8, the electrocatalytic performance of alloy with different composition was shown.

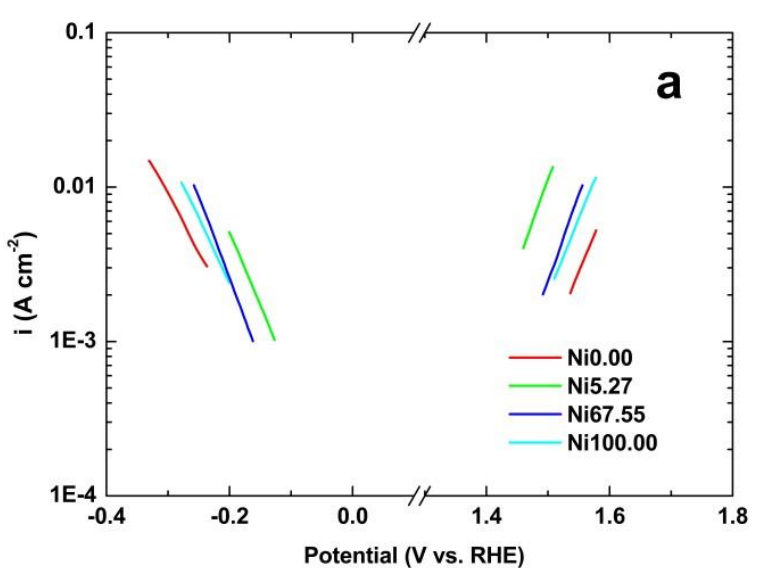

(a)

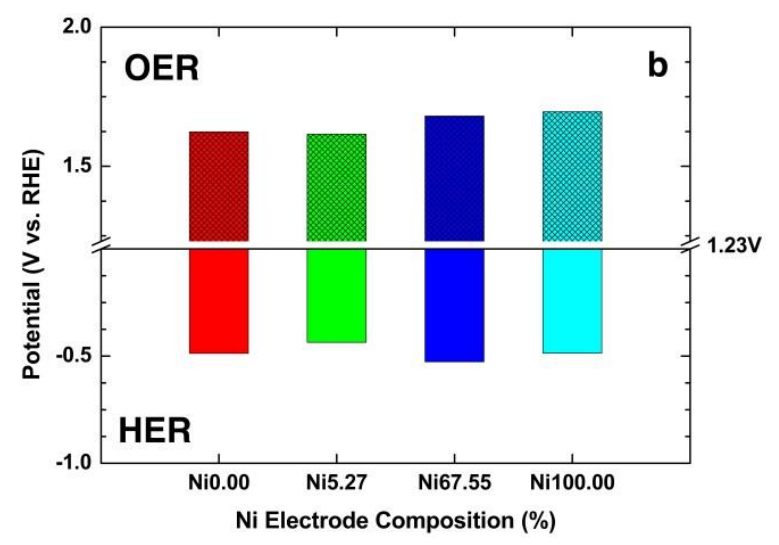

(b)

Figure 8. (a) QSSP and (b) mean value of cell potential of Ni-Co alloy nanowires with different composition obtained by electrodeposition in polycarbonate membranes.

In Figure 8a, the linear behavior of QSSP tests was reported. For HER, the potential was scanned from 0 to $-0.5 \mathrm{~V}$ (versus RHE), while for the OER, it was scanned from 1.2 to $1.7 \mathrm{~V}$ (versus RHE). In both cases, the scan rate was $0.167 \mathrm{mV} \mathrm{s}^{-1}$. As can be seen, pure $\mathrm{Ni}$ and Co electrodes have the worst performance for both HER and OER. For the alloy, for both cathode and anode, the better performances were obtained in the case of a composition of about $95 \%$ in Co and $5 \%$ in Ni. These results were confirmed as well by galvanostatic tests carried out to evaluate the mid-term behavior of the electrodes in $30 \% \mathrm{w} / \mathrm{w} \mathrm{KOH}$ solution at room temperature and at an imposed current density of $0.05 \mathrm{~A} \mathrm{~cm}^{-2}$ for six hours. During these tests, the cell potential remains approximately constant at the values shown in Figure $8 \mathrm{~b}$. Thus, it can be deduced that the lowest cell voltage was obtained for the alloy with $95 \%$ of $\mathrm{Co}$ and $5 \%$ of $\mathrm{Ni}$.

\subsection{Ni-foam Behavior with Different Electrocatalysts}

Electrocatalytic behavior of commercial Ni-foam functionalized with two different electrocatalyst was tested for both cathode and anode in $\mathrm{KOH} 30 \% \mathrm{w} / \mathrm{w}$ aqueous solution. In Figure 9 the SEM images of foam surface with and without functionalization were reported. Particularly, Figure $9 a, b$ is related to Ni foam without catalyst, while Figure $9 \mathrm{c}, \mathrm{d}$ shows in detail the Ni foam surface with $\mathrm{Pd}$ and $\mathrm{Ni}-\mathrm{Co}$ alloy, respectively.

Ni foam surface, Figure 9b, appears almost smooth with some irregularity. The catalyst deposit is evident onto the Ni foam surface, as shown in Figure 9c,d. The morphology of the deposits appears very different from each other, due to the difference both in the deposited material, but mainly to the method used for the deposition. In both cases, the deposit uniformly covers the surface of the foam, forming a thin layer that affects the entire structure of the foam (Figure S6).

The performance of $\mathrm{Ni}$ foam electrodes, before and after functionalization, was evaluated through galvanostatic step tests in $30 \% \mathrm{KOH}$ aqueous solution. Figure 10a,b shows the obtained results for HER and OER, respectively. Each test consists in nine increasing current density step $(0.5,1,2.5,5$, $10,25,50,100$ and $250 \mathrm{~mA} \mathrm{~cm}^{-2}$ ), each $300 \mathrm{~s}$ long. Each electrode was tested three times, and the results are shown as mean values with error bars. For the HER and in all the investigated current densities range, $\mathrm{Ni}$ foam/Pd and $\mathrm{Ni}$ foam/Ni-Co alloy electrodes have better performance compared to $\mathrm{Ni}$ foam without catalyst. In particular, at $0.25 \mathrm{~A} \mathrm{~cm}^{-2}, \mathrm{Ni}$ foam/Ni-Co alloy electrodes have an overpotential value less than $100 \mathrm{mV}$ with respect to not functionalized Ni foam. For the OER, 
a different behavior was observed at low and high current density. In fact, at low current densities, the performance of $\mathrm{Ni}$ foam/Ni-Co alloy, and especially Ni foam/Pd, were better than $\mathrm{Ni}$ foam. At 0.05 $\mathrm{A} \mathrm{cm}^{-2}$, the overpotential value was the same for each electrode, and almost equal to $1.52 \mathrm{~V}$. At higher current densities, Ni foam electrodes without catalyst have the best performance.

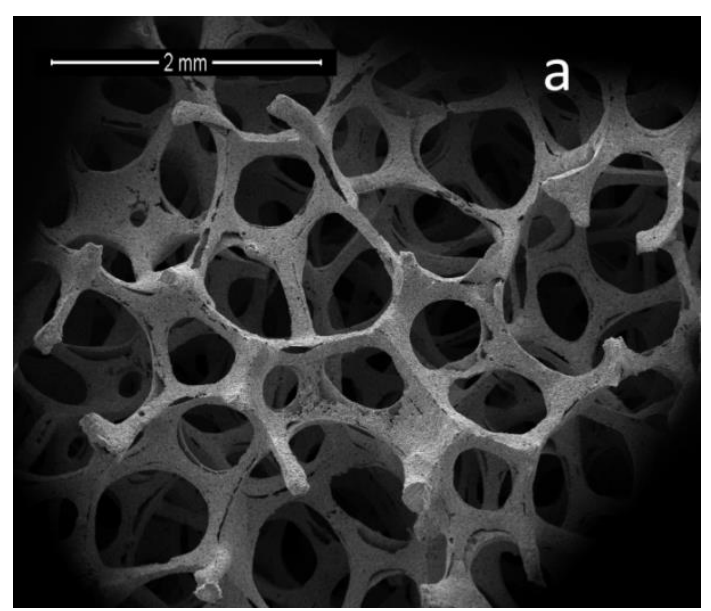

(a)

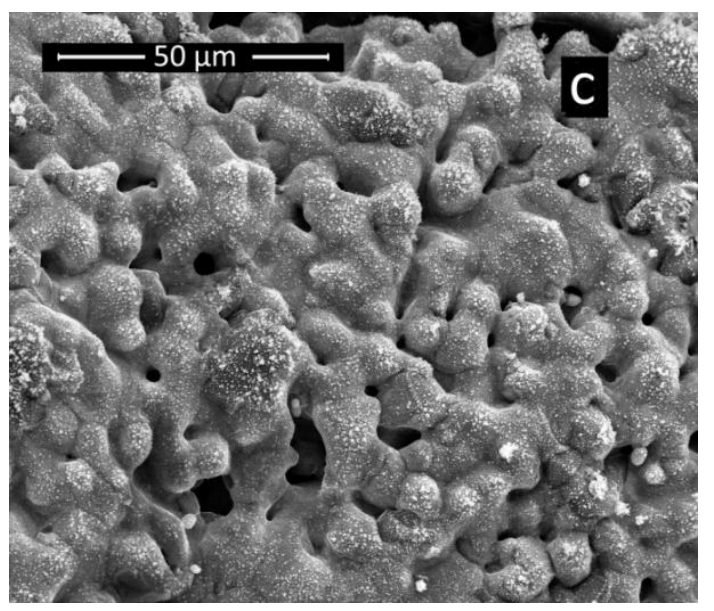

(c)

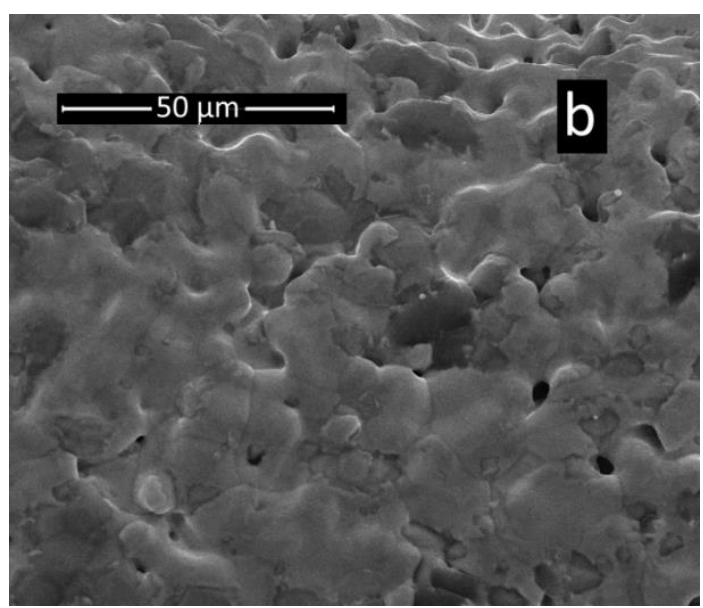

(b)

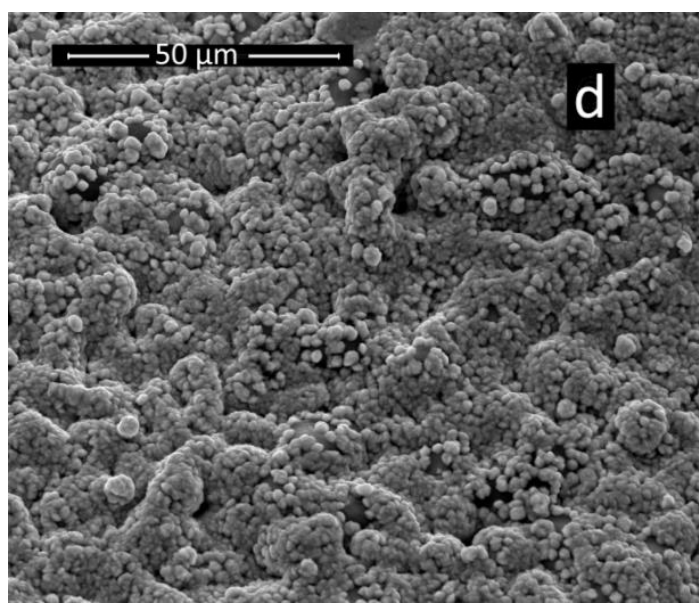

(d)

Figure 9. (a) SEM image of Ni-foam morphology. Surface detail of Ni foam (b) without catalyst, (c) with Pd, and (d) with Ni-Co alloy.

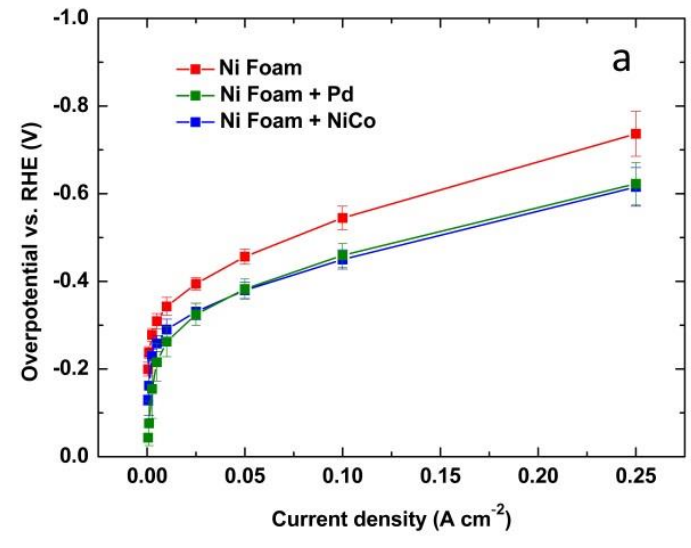

(a)

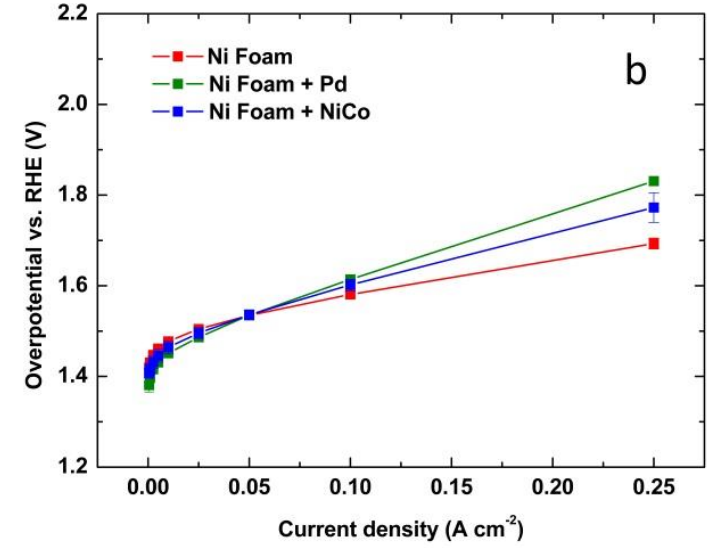

(b)

Figure 10. Galvanostatic step tests for (a) HER and (b) OER carried out in 30\% w/w KOH aqueous solution for Ni foam-based electrodes. 
These results confirm that $\mathrm{Pd}$ and Ni-Co based electrodes have good electrocatalytic activity for the HER. While, the deterioration of the performance for the electrodes with catalysts for the OER is most likely due to a surface modification under oxygen evolution and/or the anodic polarization. Further experiments are in progress to investigate this issue.

To reassume our results and compare them with more relevant literature data, Table 3 was reported. It can be observed that for both HER and OER our results are very close to that obtained from others authors.

Table 3. Reassuming of main results obtained in this work and the most relevant literature data.

\begin{tabular}{|c|c|c|c|c|}
\hline Electrocatalysts & HER/OER & KOH Solution & $\begin{array}{c}\text { Potential } \\
\text { (V Versus RHE) }\end{array}$ & Reference \\
\hline Ni Lamina & HER & $30 \% \mathrm{w} / \mathrm{w}$ & -0.269 & This work \\
\hline $\mathrm{Ni}$ Foam + Pd & HER & $30 \% \mathrm{w} / \mathrm{w}$ & -0.250 & This work \\
\hline $\mathrm{Ni}_{0.95} \mathrm{Dy}_{0.05}$ & HER & $8 \mathrm{M}$ & -0.240 & [76] \\
\hline $\mathrm{CoP} / \mathrm{CC}$ & HER & $1 \mathrm{M}$ & -0.206 & [77] \\
\hline Ni NWs & HER & $30 \% \mathrm{w} / \mathrm{w}$ & -0.196 & This work \\
\hline $\mathrm{Ni}_{2} \mathrm{P} @$ mesoG & HER & $1 \mathrm{M}$ & -0.188 & [78] \\
\hline Petaloid FeP/C & HER & $1 \mathrm{M}$ & -0.185 & [79] \\
\hline Ni NWs + Pd NPs & HER & $30 \% \mathrm{w} / \mathrm{w}$ & -0.150 & This work \\
\hline PO-Ni/Ni-N-CNFs & OER & $1 \mathrm{M}$ & 1.69 & [80] \\
\hline Ni NWs & OER & $30 \% \mathrm{w} / \mathrm{w}$ & 1.67 & This work \\
\hline $\mathrm{NiCo}-\mathrm{LDH}$ & OER & $0.1 \mathrm{M}$ & 1.65 & [81] \\
\hline $\mathrm{Ni}-\mathrm{Fe}_{x} \mathrm{P} / \mathrm{NF}$ & OER & $1 \mathrm{M}$ & 1.62 & [82] \\
\hline Mo-CoP & OER & $1 \mathrm{M}$ & 1.56 & [83] \\
\hline $\mathrm{Ni} \mathrm{NWs}+\mathrm{IrO}_{2}$ & OER & $1 \mathrm{M}$ & 1.53 & This work \\
\hline NiCo NWs (Ni5.27) & OER & $30 \% \mathrm{w} / \mathrm{w}$ & 1.49 & This work \\
\hline $\mathrm{Ni} F o a m+\mathrm{NiCo}$ & OER & $30 \% \mathrm{w} / \mathrm{w}$ & 1.48 & This work \\
\hline
\end{tabular}

\subsection{Performance of Lab Scale Electrolyzer}

In all investigated conditions and for the different samples, the experimental cell voltage is always above $2.3 \mathrm{~V}$. This relatively high value is due to the charge transfer overvoltage and ohmic overvoltage. In particular, the latter has the greatest weight as shown in [76]. We think that the high ohmic drop is due to a different cause. Firstly, we have operated at room temperature, while industrial cells work at $60{ }^{\circ} \mathrm{C}$. A higher temperature is a better condition because with the increase of temperature ionic conductivity increases leading to a decrease of the ohmic drop. In addition, the screen effect of gas bubbles that accumulate on the surface of nanowires, as shown in Figure 11, must be taken into consideration as well. In fact, with the increase of gas accumulation in the spaces between the NWs, they go empty of electrolyte, which increases the ohmic drop.

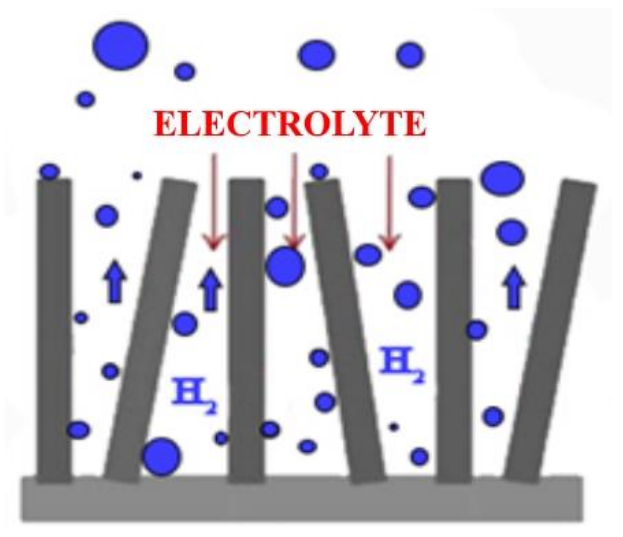

Figure 11. Schematic representation of screening effect of hydrogen bubbles. 
In order to decrease this voltage dissipation, we have focused our attention on the fluid dynamics of electrolyzers to quickly remove the gas bubbles produced at the electrodes. For this aim we have developed a homemade cell obtained with a 3D printer (Figure 12), as detailed in [55]. Preliminary results show that by using this cell [55], the performance of electrolyze increases but further experiments are in progress with continuous recycling of the electrolyte, which favors the outflow of gas, and at high temperature than the room one. Besides many geometric parameters of the cell are under studying in order to improve its efficiency.

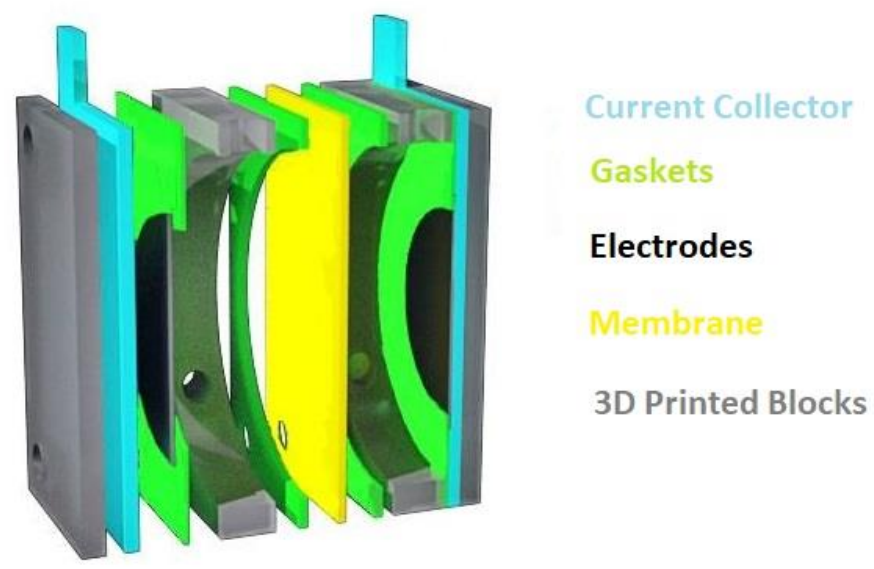

Figure 12. Scheme of homemade electrolyzer obtained by 3D printer.

\section{Conclusions}

In this work, we have shown the use of different nanostructured materials as electrodes for hydrogen and oxygen production in alkaline water splitting. Highly encouraging results were obtained, founding an immediate benefit of the high surface area which characterizes the nanostructured morphology. In particular, we have tested ordered arrays of Ni nanowires modified with iridium oxide and palladium for oxygen and hydrogen evolution reaction, respectively. Besides, ordered array of Ni-Co nanowires alloy with different composition were tested for both anode and cathode of an alkaline electrolyzer. Additionally, the preliminary results on the use of differently functionalized $\mathrm{Ni}$ foam were shown.

In all the cases considered, we found that the major drawback that affects the performance of the electrolyzer is the ohmic overvoltage, which is most likely due to the confining of the gas bubbles inside the nanostructures. To overcome this weakness, the optimization of different operation parameters, such the hydrodynamic of the fluid fluxes throughout the cell, temperature, zero gap configuration are under study.

\section{Patents}

R. Inguanta, F. Ganci, M. G. Insinga, R. L. Oliveri, C. Sunseri, Dispositivo Elettrolizzatore Migliorato, Italian Patent 102017000150541del 28/12/2017

Supplementary Materials: The following are available online at http://www.mdpi.com/1996-1073/12/19/3669/s1, Figure S1: SEM images of as prepared nanowires, Figure S2: EDS spectra of Ni nanowires before (a) and after (b) functionalization of iridium oxide by pulsed electrodeposition, Figure S3: QSSP of Ni and Ni nanowires with e without iridium oxide. For comparison, the behavior of a sheet of Ni was reported as well, Figure S4: EDS spectrum of Ni-NWs covered with Pd nanoparticles obtained by metal displacement deposition, Figure S5: SEM images of Ni-Co alloy NWs obtained by electrodeposition with a composition of 95\% Co and 5\% Ni, Figure S6: SEM images of Ni foam functionalized with (a) Pd and (b) Ni-Co.

Author Contributions: Conceptualization, R.I. and F.G.; methodology, F.G., V.C. and T.B.; investigation, F.G., V.C. and T.B.; resources, R.I., P.M., C.S. and G.A.; data curation, R.I. and F.G.; writing-original draft preparation, R.I. and F.G.; writing-review and editing, R.I., G.A. and F.G.; supervision, R.I., P.M., G.A. and C.S.; funding acquisition, C.S., G.A. and P.M." 
Funding: This research received no external funding.

Conflicts of Interest: The authors declare no conflict of interest.

\section{References}

1. Global Energy Demand Rose by $2.3 \%$ in 2018, Its Fastest Pace in the Last Decade. Available online: https://www.iea.org/newsroom/news/2019/march/global-energy-demand-rose-by-23-in-2018-itsfastest-pace-in-the-last-decade.html (accessed on 8 September 2019).

2. Burchardt, J.; Gerbert, P.; Schönberger, S.; Herhold, P.; Brognaux, C. The Economic Case for Combating Climate Change. Available online: https://www.bcg.com/it-it/publications/2018/economic-case-combatingclimate-change.aspx (accessed on 8 September 2019).

3. Hoffert, M.I.; Caldeira, K.; Benford, G.; Criswell, D.R.; Green, C.; Herzog, H.; Jain, A.K.; Kheshgi, H.S.; Lackner, K.S.; Lewis, J.S.; et al. Advanced Technology Paths to Global Climate Stability: Energy for a Greenhouse Planet. Science 2002, 298, 981-987. [CrossRef] [PubMed]

4. Fujimori, S.; Kainuma, M.; Masui, T.; Hasegawa, T.; Dai, H. The effectiveness of energy service demand reduction: A scenario analysis of global climate change mitigation. Energy Policy 2014, 75, 379-391. [CrossRef]

5. Panwar, N.L.; Kaushik, S.C.; Kothari, S. Role of renewable energy sources in environmental protection: A review. Renew. Sustain. Energy Rev. 2011, 15, 1513-1524. [CrossRef]

6. Turner, J.A. Sustainable Hydrogen Production. Science 2004, 305, 972-974. [CrossRef] [PubMed]

7. Penner, S.S. Steps toward the hydrogen economy. Energy 2006, 31, 33-43. [CrossRef]

8. Muradov, N.; Vezirolu, T. From hydrocarbon to hydrogen?carbon to hydrogen economy. Int. J. Hydrog. Energy 2005, 30, 225-237. [CrossRef]

9. Tromp, T.K. Potential Environmental Impact of a Hydrogen Economy on the Stratosphere. Science 2003, 300, $1740-1742$. [CrossRef]

10. Ritter, J.A.; Ebner, A.D.; Wang, J.; Zidan, R. Implementing a hydrogen economy. Mater. Today 2003, 6, 18-23. [CrossRef]

11. Kothari, R.; Buddhi, D.; Sawhney, R.L. Comparison of environmental and economic aspects of various hydrogen production methods. Renew. Sustain. Energy Rev. 2008, 12, 553-563. [CrossRef]

12. Tee, S.Y.; Win, K.Y.; Teo, W.S.; Koh, L.D.; Liu, S.; Teng, C.P.; Han, M.Y. Recent Progress in Energy-Driven Water Splitting. Adv. Sci. 2017, 4, 1600337. [CrossRef]

13. Tinker, L.L.; McDaniel, N.D.; Bernhard, S. Progress towards solar-powered homogeneous water photolysis. J. Mater. Chem. 2009, 19, 3328. [CrossRef]

14. Schmidt, O.; Gambhir, A.; Staffell, I.; Hawkes, A.; Nelson, J.; Few, S. Future cost and performance of water electrolysis: An expert elicitation study. Int. J. Hydrog. Energy 2017, 42, 30470-30492. [CrossRef]

15. Chi, J.; Yu, H. Water electrolysis based on renewable energy for hydrogen production. Chin. J. Catal. 2018, 39, 390-394. [CrossRef]

16. Ursua, A.; Gandia, L.M.; Sanchis, P. Hydrogen Production from Water Electrolysis: Current Status and Future Trends. Proc. IEEE 2012, 100, 410-426. [CrossRef]

17. Suffredini, H. Recent developments in electrode materials for water electrolysis. Int. J. Hydrog. Energy 2000, 25, 415-423. [CrossRef]

18. Fan, C.; Piron, D.L. Electrodeposition as a means of producing large-surface electrodes required in water electrolysis. Surf. Coat. Technol. 1995, 73, 91-97. [CrossRef]

19. Sapountzi, F.M.; Gracia, J.M.; Fredriksson, H.O.; Niemantsverdriet, J.H. Electrocatalysts for the generation of hydrogen, oxygen and synthesis gas. Prog. Energy Combust. Sci. 2017, 58, 1-35. [CrossRef]

20. Ahmad, H.; Kamarudin, S.K.; Minggu, L.J.; Kassim, M. Hydrogen from photo-catalytic water splitting process: A review. Renew. Sustain. Energy Rev. 2015, 43, 599-610. [CrossRef]

21. Han, T.; Shi, Y.; Song, X.; Mio, A.; Valenti, L.; Hui, F.; Privitera, S.; Lombardo, S.; Lanza, M. Ageing mechanisms of highly active and stable nickel-coated silicon photoanodes for water splitting. J. Mater. Chem. A 2016, 4, 8053-8060. [CrossRef]

22. Han, T.; Privitera, S.; Milazzo, R.G.; Bongiorno, C.; Di Franco, S.; La Via, F.; Song, X.; Shi, Y.; Lanza, M.; Lombardo, S. Photo-electrochemical water splitting in silicon based photocathodes enhanced by plasmonic/catalytic nanostructures. Mater. Sci. Eng. B 2017, 225, 128-133. [CrossRef] 
23. Godula-Jopek, A.; Stolten, D. (Eds.) Hydrogen Production: By Electrolysis, 1st ed.; Wiley-VCH: Weinheim, Germany, 2015; ISBN 978-3-527-67650-7.

24. Santhanam, K.S.V.; Press, R.J.; Miri, M.J.; Bailey, A.V.; Takacs, G.A. Introduction to Hydrogen Technology, 2nd ed.; John Wiley \& Sons: Hoboken, NJ, USA, 2017; ISBN 978-1-119-26557-3.

25. Shiva Kumar, S.; Himabindu, V. Hydrogen production by PEM water electrolysis-A review. Mater. Sci. Energy Technol. 2019, 2, 442-454. [CrossRef]

26. Carmo, M.; Fritz, D.L.; Mergel, J.; Stolten, D. A comprehensive review on PEM water electrolysis. Int. J. Hydrog. Energy 2013, 38, 4901-4934. [CrossRef]

27. Corona-Guinto, J.L.; Cardeño-García, L.; Martínez-Casillas, D.C.; Sandoval-Pineda, J.M.; Tamayo-Meza, P.; Silva-Casarin, R.; González-Huerta, R.G. Performance of a PEM electrolyzer using RuIrCoOx electrocatalysts for the oxygen evolution electrode. Int. J. Hydrog. Energy 2013, 38, 12667-12673. [CrossRef]

28. Bender, G.; Carmo, M.; Smolinka, T.; Gago, A.; Danilovic, N.; Mueller, M.; Ganci, F.; Fallisch, A.; Lettenmeier, P.; Friedrich, K.A.; et al. Initial approaches in benchmarking and round robin testing for proton exchange membrane water electrolyzers. Int. J. Hydrog. Energy 2019, 44, 9174-9187. [CrossRef]

29. Sheela, G. Zinc-nickel alloy electrodeposits for water electrolysis. Int. J. Hydrog. Energy 2002, 27, 627-633. [CrossRef]

30. Solmaz, R.; Salcı, A.; Yüksel, H.; Doğrubaş, M.; Kardaş, G. Preparation and characterization of Pd-modified Raney-type NiZn coatings and their application for alkaline water electrolysis. Int. J. Hydrog. Energy 2017, 42, 2464-2475. [CrossRef]

31. Li, X.; Walsh, F.C.; Pletcher, D. Nickel based electrocatalysts for oxygen evolution in high current density, alkaline water electrolysers. Phys Chem Chem Phys 2011, 13, 1162-1167. [CrossRef]

32. Zeng, K.; Zhang, D. Recent progress in alkaline water electrolysis for hydrogen production and applications. Prog. Energy Combust. Sci. 2010, 36, 307-326. [CrossRef]

33. Solmaz, R.; Kardaş, G. Fabrication and characterization of NiCoZn-M (M: Ag, Pd and Pt) electrocatalysts as cathode materials for electrochemical hydrogen production. Int. J. Hydrog. Energy 2011, 36, 12079-12087. [CrossRef]

34. Milazzo, R.G.; Privitera, S.M.S.; D’Angelo, D.; Scalese, S.; Di Franco, S.; Maita, F.; Lombardo, S. Spontaneous galvanic displacement of Pt nanostructures on nickel foam: Synthesis, characterization and use for hydrogen evolution reaction. Int. J. Hydrog. Energy 2018, 43, 7903-7910. [CrossRef]

35. Mayousse, E.; Maillard, F.; Fouda-Onana, F.; Sicardy, O.; Guillet, N. Synthesis and characterization of electrocatalysts for the oxygen evolution in PEM water electrolysis. Int. J. Hydrog. Energy 2011, 36, 10474-10481. [CrossRef]

36. Xu, D.; Stevens, M.B.; Cosby, M.R.; Oener, S.Z.; Smith, A.M.; Enman, L.J.; Ayers, K.E.; Capuano, C.B.; Renner, J.N.; Danilovic, N.; et al. Earth-Abundant Oxygen Electrocatalysts for Alkaline Anion-Exchange-Membrane Water Electrolysis: Effects of Catalyst Conductivity and Comparison with Performance in Three-Electrode Cells. Acs Catal. 2019, 9, 7-15. [CrossRef]

37. Schiller, G.; Ansar, A.; Lang, M.; Patz, O. High temperature water electrolysis using metal supported solid oxide electrolyser cells (SOEC). J. Appl. Electrochem. 2009, 39, 293-301. [CrossRef]

38. Brisse, A.; Schefold, J.; Zahid, M. High temperature water electrolysis in solid oxide cells. Int. J. Hydrog. Energy 2008, 33, 5375-5382. [CrossRef]

39. Schalenbach, M.; Zeradjanin, A.R.; Kasian, O.; Cherevko, S.; Mayrhofer, K.J. A Perspective on Low-Temperature Water Electrolysis-Challenges in Alkaline and Acidic Technology. Int. J. Electrochem. Sci. 2018, 1173-1226. [CrossRef]

40. Bodner, M.; Hofer, A.; Hacker, V. $\mathrm{H}_{2}$ generation from alkaline electrolyzer: $\mathrm{H}_{2}$ generation from alkaline electrolyzer. Wiley Interdiscip. Rev. Energy Environ. 2015, 4, 365-381. [CrossRef]

41. Safizadeh, F.; Ghali, E.; Houlachi, G. Electrocatalysis developments for hydrogen evolution reaction in alkaline solutions-A Review. Int. J. Hydrog. Energy 2015, 40, 256-274. [CrossRef]

42. Amikam, G.; Nativ, P.; Gendel, Y. Chlorine-free alkaline seawater electrolysis for hydrogen production. Int. J. Hydrog. Energy 2018, 43, 6504-6514. [CrossRef]

43. Ding, R.; Cui, S.; Lin, J.; Sun, Z.; Du, P.; Chen, C. Improving the water splitting performance of nickel electrodes by optimizing their pore structure using a phase inversion method. Catal. Sci. Technol. 2017, 7, 3056-3064. [CrossRef]

44. Jing, S.; Zhang, L.; Luo, L.; Lu, J.; Yin, S.; Shen, P.K.; Tsiakaras, P. N-Doped Porous Molybdenum Carbide Nanobelts as Efficient Catalysts for Hydrogen Evolution Reaction. Appl. Catal. B Environ. 2018, 224, 533-540. [CrossRef] 
45. Mollamahale, Y.B.; Jafari, N.; Hosseini, D. Electrodeposited Ni-W nanoparticles: Enhanced catalytic activity toward hydrogen evolution reaction in acidic media. Mater. Lett. 2018, 213, 15-18. [CrossRef]

46. Siwek, K.I.; Eugénio, S.; Santos, D.M.F.; Silva, M.T.; Montemor, M.F. 3D nickel foams with controlled morphologies for hydrogen evolution reaction in highly alkaline media. Int. J. Hydrog. Energy 2019, 44, 1701-1709. [CrossRef]

47. Chen, S.; Thind, S.S.; Chen, A. Nanostructured materials for water splitting-State of the art and future needs: A mini-review. Electrochem. Commun. 2016, 63, 10-17. [CrossRef]

48. Sunseri, C.; Cocchiara, C.; Ganci, F.; Moncada, A.; Oliveri, R.L.; Patella, B.; Piazza, S. Rosalinda Inguanta Nanostructured electrochemical devices for sensing, energy conversion and storage. Chem. Eng. Trans. 2016, $47,43-48$.

49. Inguanta, R.; Piazza, S.; Sunseri, C.; Cino, A.; Di Dio, V.; Cascia, D.L.; Miceli, R.; Rando, C.; Zizzo, G. An electrochemical route towards the fabrication of nanostructured semiconductor solar cells. In Proceedings of the SPEEDAM 2010, Pisa, Italy, 14-16 June 2010; pp. 1166-1171.

50. Patella, B.; Inguanta, R.; Piazza, S.; Sunseri, C. A nanostructured sensor of hydrogen peroxide. Sens. Actuators B Chem. 2017, 245, 44-54. [CrossRef]

51. Silipigni, L.; Barreca, F.; Fazio, E.; Neri, F.; Spanò, T.; Piazza, S.; Sunseri, C.; Inguanta, R. Template Electrochemical Growth and Properties of Mo Oxide Nanostructures. J. Phys. Chem. C 2014, 118, 22299-22308. [CrossRef]

52. Inguanta, R.; Piazza, S.; Sunseri, C. Influence of electrodeposition techniques on Ni nanostructures. Electrochim. Acta 2008, 53, 5766-5773. [CrossRef]

53. Ganci, F.; Lombardo, S.; Sunseri, C.; Inguanta, R. Nanostructured electrodes for hydrogen production in alkaline electrolyzer. Renew. Energy 2018, 123, 117-124. [CrossRef]

54. Battaglia, M.; Inguanta, R.; Piazza, S.; Sunseri, C. Fabrication and characterization of nanostructured Ni-IrO2 electrodes for water electrolysis. Int. J. Hydrog. Energy 2014, 39, 16797-16805. [CrossRef]

55. Ganci, F.; Cusumano, V.; Sunseri, C.; Inguanta, R. Performance Enhancement of Alkaline Water Electrolyzer Using Nanostructured Electrodes Synthetized by Template Electrosynthesis. In Proceedings of the 2018 IEEE 4th International Forum on Research and Technology for Society and Industry (RTSI), Palermo, Italy, 10-13 September 2018; pp. 1-4.

56. Li, A.; Sun, Y.; Yao, T.; Han, H. Earth-Abundant Transition-Metal-Based Electrocatalysts for Water Electrolysis to Produce Renewable Hydrogen. Chem. Eur. J. 2018, 24, 18334-18355. [CrossRef] [PubMed]

57. Fabrizio, G.; Valentino, C.; Carmelo, S. Inguanta Rosalinda Fabrication of Nanostructured Ni-co Electrodes for Hydrogen and Oxygen Evolution Reaction in Water-alkaline Electrolyzer. Chem. Eng. Trans. 2019, 73, 109-114.

58. Ganci, F.; Inguanta, R.; Piazza, S.; Sunseri, C. Salvatore Lombardo Fabrication and characterization of nanostructured ni and pd electrodes for hydrogen evolution reaction (her) in water-alkaline electrolyzer. Chem. Eng. Trans. 2017, 57, 1591-1596.

59. Moncada, A.; Piazza, S.; Sunseri, C.; Inguanta, R. Recent improvements in $\mathrm{PbO} 2$ nanowire electrodes for lead-acid battery. J. Power Sources 2015, 275, 181-188. [CrossRef]

60. Vázquez-Gómez, L.; Cattarin, S.; Guerriero, P.; Musiani, M. Influence of deposition current density on the composition and properties of electrodeposited $\mathrm{Ni}+\mathrm{RuO}_{2}$ and $\mathrm{Ni}+\mathrm{IrO}_{2}$ composites. J. Electroanal. Chem. 2009, 634, 42-48. [CrossRef]

61. Schmidt, T.; Wendt, H. Electrocatalysis of cathodic hydrogen and anodic oxygen evolution in alkaline water electrolysis by in situ activation procedures. Electrochim. Acta 1994, 39, 1763-1767. [CrossRef]

62. Inguanta, R.; Rinaldo, E.; Piazza, S.; Sunseri, C. Lead Nanowires for Microaccumulators Obtained Through Indirect Electrochemical Template Deposition. Electrochem. Solid-State Lett. 2010, 13, K1-K4. [CrossRef]

63. Battaglia, M.; Piazza, S.; Sunseri, C.; Inguanta, R. Amorphous silicon nanotubes via galvanic displacement deposition. Electrochem. Commun. 2013, 34, 134-137. [CrossRef]

64. Inguanta, R.; Ferrara, G.; Piazza, S.; Sunseri, C. A new route to grow oxide nanostructures based on metal displacement deposition. Lanthanides oxy/hydroxides growth. Electrochim. Acta 2012, 76, 77-87. [CrossRef]

65. Yamanaka, K. Anodically Electrodeposited Iridium Oxide Films (AEIROF) from Alkaline Solutions for Electrochromic Display Devices. Jpn. J. Appl. Phys. 1989, 28, 632-637. [CrossRef]

66. Ooka, H.; Yamaguchi, A.; Takashima, T.; Hashimoto, K.; Nakamura, R. Efficiency of Oxygen Evolution on Iridium Oxide Determined from the pH Dependence of Charge Accumulation. J. Phys. Chem. C 2017, 121, 17873-17881. [CrossRef] 
67. Abbott, D.F.; Lebedev, D.; Waltar, K.; Povia, M.; Nachtegaal, M.; Fabbri, E.; Copéret, C.; Schmidt, T.J. Iridium Oxide for the Oxygen Evolution Reaction: Correlation between Particle Size, Morphology, and the Surface Hydroxo Layer from Operando XAS. Chem. Mater. 2016, 28, 6591-6604. [CrossRef]

68. Schrebler Guzmán, R.S.; Vilche, J.R.; Arvía, A.J. Rate Processes Related to the Hydrated Nickel Hydroxide Electrode in Alkaline Solutions. J. Electrochem. Soc. 1978, 125, 1578. [CrossRef]

69. Sarkar, S.; Peter, S.C. An overview on Pd-based electrocatalysts for the hydrogen evolution reaction. Inorg. Chem. Front. 2018, 5, 2060-2080. [CrossRef]

70. Naga Mahesh, K.; Balaji, R.; Dhathathreyan, K.S. Palladium nanoparticles as hydrogen evolution reaction (HER) electrocatalyst in electrochemical methanol reformer. Int. J. Hydrog. Energy 2016, 41, 46-51. [CrossRef]

71. Hall, D.S.; Bock, C.; MacDougall, B.R. The Electrochemistry of Metallic Nickel: Oxides, Hydroxides, Hydrides and Alkaline Hydrogen Evolution. J. Electrochem. Soc. 2013, 160, F235-F243. [CrossRef]

72. Pérez-Alonso, F.J.; Adán, C.; Rojas, S.; Peña, M.A.; Fierro, J.L.G. Ni-Co electrodes prepared by electroless-plating deposition. A study of their electrocatalytic activity for the hydrogen and oxygen evolution reactions. Int. J. Hydrog. Energy 2015, 40, 51-61. [CrossRef]

73. Hong, S.H.; Ahn, S.H.; Choi, I.; Pyo, S.G.; Kim, H.J.; Jang, J.H.; Kim, S.K. Fabrication and evaluation of nickel cobalt alloy electrocatalysts for alkaline water splitting. Appl. Surf. Sci. 2014, 307, 146-152. [CrossRef]

74. Lupi, C.; Dell'Era, A.; Pasquali, M. Nickel-cobalt electrodeposited alloys for hydrogen evolution in alkaline media. Int. J. Hydrog. Energy 2009, 34, 2101-2106. [CrossRef]

75. Bousher, A. Review: Unidentate complexes involving borate. J. Coord. Chem. 1995, 34, 1-11. [CrossRef]

76. Cardoso, D.S.P.; Amaral, L.; Santos, D.M.F.; Šljukić, B.; Sequeira, C.A.C.; Macciò, D.; Saccone, A. Enhancement of hydrogen evolution in alkaline water electrolysis by using nickel-rare earth alloys. Int. J. Hydrog. Energy 2015, 40, 4295-4302. [CrossRef]

77. Tian, J.; Liu, Q.; Asiri, A.M.; Sun, X. Self-Supported Nanoporous Cobalt Phosphide Nanowire Arrays: An Efficient 3D Hydrogen-Evolving Cathode over the Wide Range of pH 0-14. J. Am. Chem. Soc. 2014, 136, 7587-7590. [CrossRef] [PubMed]

78. Jeoung, S.; Seo, B.; Hwang, J.M.; Joo, S.H.; Moon, H.R. Direct conversion of coordination compounds into Ni $2 \mathrm{P}$ nanoparticles entrapped in 3D mesoporous graphene for an efficient hydrogen evolution reaction. Mater. Chem. Front. 2017, 1, 973-978. [CrossRef]

79. Wang, F.; Yang, X.; Dong, B.; Yu, X.; Xue, H.; Feng, L. A FeP powder electrocatalyst for the hydrogen evolution reaction. Electrochem. Commun. 2018, 92, 33-38. [CrossRef]

80. Wu, Z.Y.; Ji, W.B.; Hu, B.C.; Liang, H.W.; Xu, X.X.; Yu, Z.L.; Li, B.Y.; Yu, S.H. Partially oxidized Ni nanoparticles supported on $\mathrm{Ni}-\mathrm{N}$ co-doped carbon nanofibers as bifunctional electrocatalysts for overall water splitting. Nano Energy 2018, 51, 286-293. [CrossRef]

81. Jiang, J.; Zhang, A.; Li, L.; Ai, L. Nickel-cobalt layered double hydroxide nanosheets as high-performance electrocatalyst for oxygen evolution reaction. J. Power Sources 2015, 278, 445-451. [CrossRef]

82. Zhang, C.; Xie, Y.; Deng, H.; Zhang, C.; Su, J.W.; Dong, Y.; Lin, J. Ternary nickel iron phosphide supported on nickel foam as a high-efficiency electrocatalyst for overall water splitting. Int. J. Hydrog. Energy 2018, 43, 7299-7306. [CrossRef]

83. Guan, C.; Xiao, W.; Wu, H.; Liu, X.; Zang, W.; Zhang, H.; Ding, J.; Feng, Y.P.; Pennycook, S.J.; Wang, J. Hollow Mo-doped CoP nanoarrays for efficient overall water splitting. Nano Energy 2018, 48, 73-80. [CrossRef]

(C) 2019 by the authors. Licensee MDPI, Basel, Switzerland. This article is an open access article distributed under the terms and conditions of the Creative Commons Attribution (CC BY) license (http://creativecommons.org/licenses/by/4.0/). 